\title{
Use of radionuclide scanning in the preoperative estimation of pulmonary function after pneumonectomy
}

\author{
P A CORRIS, D A ELLIS, T HAWKINS, G J GIBSON
}

From the Departments of Respiratory Medicine and Medical Physics, Freeman Hospital, Newcastle upon Tyne

ABSTRACT Twenty eight patients with bronchial carcinoma were studied before pneumonectomy. Measurement of spirometric indices, static lung volumes, transfer factor (TLCO), and transfer coefficient $(\mathrm{KCO})$ was undertaken before and four months after pneumonectomy. Fourteen of the patients also performed a symptom limited progressive exercise test on a cycle ergometer before and four months after pneumonectomy. All patients had standard xenon-133 ventilation and technetium-99m perfusion scans performed before operation. Eleven patients had krypton-81m

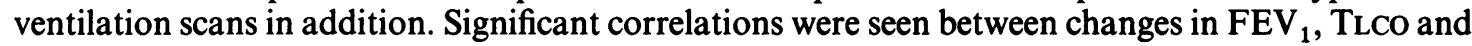
$\mathrm{KCO}$ and the preoperative function of the resected lung as determined by percentage preoperative perfusion to that lung $(\mathrm{p}<0.001)$. There were mean decreases in $\mathrm{FEV}_{1}$ of $22 \%$ and in vital capacity (VC) of $28.7 \%$ predicted. Estimation of postoperative $F_{E V}$ from the preoperative values showed equally good agreement with measured postoperative values whether ${ }^{99 \mathrm{~m}} \mathrm{Tc}$ perfusion or ${ }^{81 \mathrm{~m}} \mathrm{Kr}$ ventilation scans were used in the 11 patients in whom both scans were available. Significant correlations were seen between change in maximum exercise ventilation (VEmax) or maximum oxygen uptake $\left(\mathrm{V}_{2} \mathrm{max}\right)$ after pneumonectomy and percentage preoperative perfusion to the resected lung $(\mathrm{p}<0.001)$. Estimation of postoperative maximum ventilation and maximum oxygen uptake from the postoperative values on the basis of ${ }^{99 \mathrm{~m}} \mathrm{Tc}$ perfusion scans showed good agreement with observed values. Perfusion scans are useful in estimating not only the changes in spirometric indices that follow pneumonectomy for bronchial carcinoma but also changes in carbon monoxide transfer and exercise capacity.

Estimation of likely postoperative lung function and exercise performance is implicit in the selection of patients for thoracic surgery. Problems are encountered particularly in patients who may require pneumonectomy for bronchial carcinoma and who have some degree of generalised airway obstruction. Preoperative spirometric measurements and a clinical assessment of exercise tolerance are the most frequently used guides, but quantitative prediction of postoperative function requires also an estimate of the functional contribution of the lung to be resected. This has been assessed by bronchospirometry, ${ }^{12}$ by unilateral occlusion of a main bronchus or of a pul-

Address for reprint requests: Dr P A Corris, Regional Cardiothoracic Centre, Freeman Hospital, Newcastle upon Tyne NE7 7DN.

Accepted 30 November 1986 monary artery, ${ }^{3}$ by the lateral position test, ${ }^{4}$ and (most frequently and conveniently) by use of radioisotope scanning. ${ }^{5-9}$ Perfusion lung scans have been shown to be accurate in predicting postoperative $\mathrm{FEV}_{1}$, vital capacity (VC), functional residual capacity, and maximum voluntary ventilation. ${ }^{6}$ For estimation of postoperative ventilatory function ventilation scans might seem more appropriate, but the most commonly used isotope, xenon-133 $\left({ }^{133} \mathrm{Xe}\right)$ has generally given results slightly less accurate than technetium $\left({ }^{99 \mathrm{~m}} \mathrm{Tc}\right)$ perfusion scans. ${ }^{9}$ The short lived isotope krypton $\left({ }^{81 \mathrm{~m}} \mathrm{Kr}\right)$ has theoretical advantages over xenon ${ }^{10}$ and has been suggested as the most appropriate for use in the prediction of ventilatory function, ${ }^{11}$ but it is not clear whether in this context krypton ventilation scans are superior to technetium perfusion scans.

Attempts have been made to estimate postoperative carbon monoxide transfer factor (TLCO) 
but the relationships between estimated and measured values were less good than those for spirometric indices. ${ }^{6}$ Perhaps accurate prediction of exercise performance would be more important, but a previous attempt to estimate exercise capacity after pneumonectomy using quantitative perfusion scanning was unsuccessful. ${ }^{12}$ We have studied a group of patients before and after pneumonectomy for bronchial carcinoma, (1) to assess the relative value of technetium perfusion and krypton ventilation scans; (2) to investigate the relationships of changes in TLCO and transfer coefficient (KCO) to preoperative measurements of lung function; and (3) to assess the value of lung scans in predicting postoperative exercise performance.

\section{Methods}

Twenty eight patients with bronchial carcinoma were studied before pneumonectomy. All were considered to have technically resectable tumours according to clinical, radiographic, and bronchoscopic criteria. There were 24 men and four women and all were current smokers or ex-smokers. The mean age was 57 (range 41-64) years. In all patients we measured $\mathrm{FEV}_{1}$ and $\mathrm{VC}$ preoperatively by a bellows spirometer (Vitalograph) and TLCO and KCo by the single breath method, ${ }^{13}$ using the simultaneously estimated single breath alveolar volume $\left(\mathrm{VA}_{\mathrm{A}}\right){ }^{14}$ Results were expressed as percentages of predicted values. ${ }^{15-19}$ Fourteen patients performed a symptom limited progressive exercise test on a cycle ergometer. The initial work load was 25 watts and this was increased by 25 watts every minute until the maximum work load was achieved. Ventilation $(\dot{\mathrm{V}} \mathrm{E})$ was measured by integration of the flow signal from a Fleisch pneumotachograph over the second half minute of work at each work load, the oxygen concentration of the mixed expired gas was measured with a Centronic MGA 200 mass spectrometer and oxygen uptake was calculated by a microprocessor (PK Morgan Ltd). The electrocardiogram was monitored continuously.

Perfusion lung scans were performed in all patients by intravenous injection of $37 \mathrm{MBq}$ of ${ }^{99 \mathrm{~m}} \mathrm{Tc}$ labelled microspheres in the supine posture. With the patient horizontal, two views were obtained: anteroposterior and posteroanterior. In 11 patients ventilation scans were also performed, with the patient in the same position, with ${ }^{81 \mathrm{~m}} \mathrm{Kr}$ (Medical Research Council cyclotron, Royal Postgraduate Medical School, Hammersmith) and corresponding views were obtained. The gas was delivered during tidal breathing through a disposable facemask ${ }^{10}$ counts were obtained with a Technicare Sigma 410 gamma camera and the data collected on a link system Dyanne computer. For analysis of the scans each lung was out- lined and an appropriate correction made for back ground counts. The percentage contribution of eachf? lung to total perfusion or ventilation was obtained bje calculating the number of counts in each lung fielse. and averaging the values obtained in the ante $\overrightarrow{-}$ roposterior and posteroanterior views for eithep ${ }^{99 \mathrm{~m}} \mathrm{Tc}$ or ${ }^{81 \mathrm{~m}} \mathrm{Kr}$ scans. Postoperative $\mathrm{FEV}_{1}$ or $\mathrm{VC}$ wa乡 then estimated from each scan by means of the equa tion: ${ }^{6}$

Postoperative value $=$ preoperative value $\times$ percentage function of non-affected lung. Thus after removal of a lung which contributed $30 \%$ of the total ventilation or perfusion the postoperative $\mathrm{FEV}_{1}$ or VC would be estimated as $70 \%$ of the prein operative value.

We were interested to see whether the observed changes in maximum ventilation (VंEmax) and maximum oxygen uptake $\left(\dot{\mathrm{Vo}}_{2} \max \right)$ on exercise aftę? pneumonectomy were directly related to the perב. centage preoperative function of the resected lung and hence whether equation 1 could be used to predict the postpneumonectomy values from the respective preoperative values.

Spirometry, TLCO and maximal progressive exercise tests were repeated four months afted pneumonectomy to allow full recovery from the effects of thoracotomy on lung function. ${ }^{20}$ The mag? nitude of the measured changes after pneue monectomy was compared with the preoperative function of the lung removed (percentage perfusio or ventilation of affected lung) by linear regression. In the case of $\mathrm{FEV}_{1}, \mathrm{VC}$, VEmax and $\dot{\mathrm{VO}}_{2} \max$ th estimates of postoperative function based on equa tion 1 were compared with the observed values; index pendence of the difference between observed and esti mated postoperative values and the magnitude of the

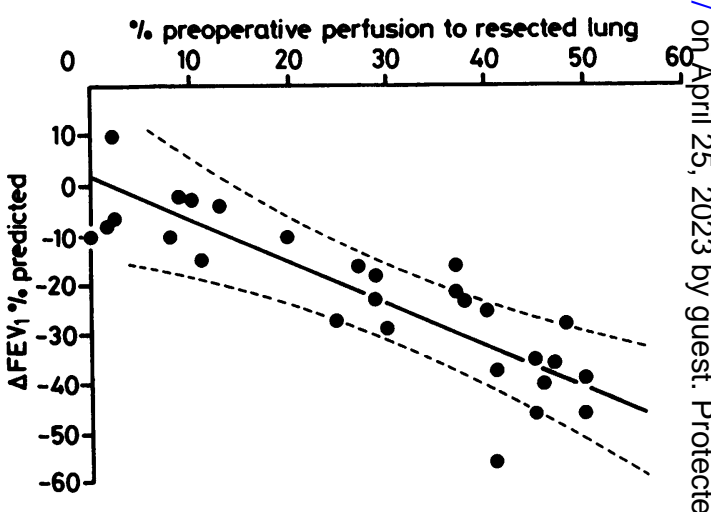

Fig 1 Relationship between observed changes in FEV $(9)$ and percentage preoperative perfusion to resected lung $(x)$ in 28 patients $(r=-0.86, y=-0.788 x+0.14)$. The broken lines indicate $95 \%$ confidence limits. 
relevant index was first established by demonstrating the lack of a significant relationship in a plot of the difference between observed and estimated values and the mean of the observed and estimated values. ${ }^{21} \mathrm{Lin}$ ear regression analysis was then performed and $95 \%$ confidence limits were plotted.

\section{Results}

The relationship between changes in $\mathrm{FEV}_{1}$, TLCo, and KCO observed four months after pneumonectomy and the preoperative function of the resected lung (as determined by the preoperative percentage perfusion to that lung) are shown for all 28 patients, with $95 \%$ confidence limits, in figures 1 and 2.

Significant linear correlations were seen for all three measurements $\left(\mathrm{FEV}_{1} \mathrm{r}=-0.86\right.$, TLCO $\mathrm{r}=-0.68$, and $\mathrm{KCO} \mathrm{r}=0.71, \mathrm{p}<0.001)$. There were mean decreases in $\mathrm{FEV}_{1}$ of $22 \%$ predicted, in $\mathrm{VC}$ of $28.7 \%$ predicted, and in TLCO of $20.2 \%$ predicted, but mean increases in $\mathrm{KcO}$ of $13.6 \%$ predicted. The mean decrease in VA was $26.7 \%$ of predicted TLC (table).

The estimate of postoperative spirometric values was equally good whether derived from ${ }^{99 \mathrm{~m}} \mathrm{Tc}$ perfusion or ${ }^{81 \mathrm{~m}} \mathrm{Kr}$ ventilation scans in the 11 patients for whom both scans were available (fig 3 ). The estimate of postoperative spirometric values derived from ${ }^{99 \mathrm{~m}} \mathrm{Tc}$ perfusion scans for all 28 patients is compared with observed values in figure 4.

Observed changes in VEmax and $\dot{\mathrm{V}}_{2} \max$ four months after pneumonectomy were compared with the preoperative percentage perfusion to that lung in the patients who performed exercise tests (fig 5). Significant linear relationships were seen for both measurements $(r=-0.89$ and -0.90 respectively $(p<0.001)$. Overall there was a mean decrease in VEmax of $13.61 \mathrm{~min}^{-1}$ and a decrease in $\dot{V}_{2} \max$ of $324 \mathrm{ml} \mathrm{min}^{-1}$ (table).

Comparison of the measured postoperative VEmax and $\ddot{\mathrm{Vo}}_{2}$ max with the values estimated preoperatively
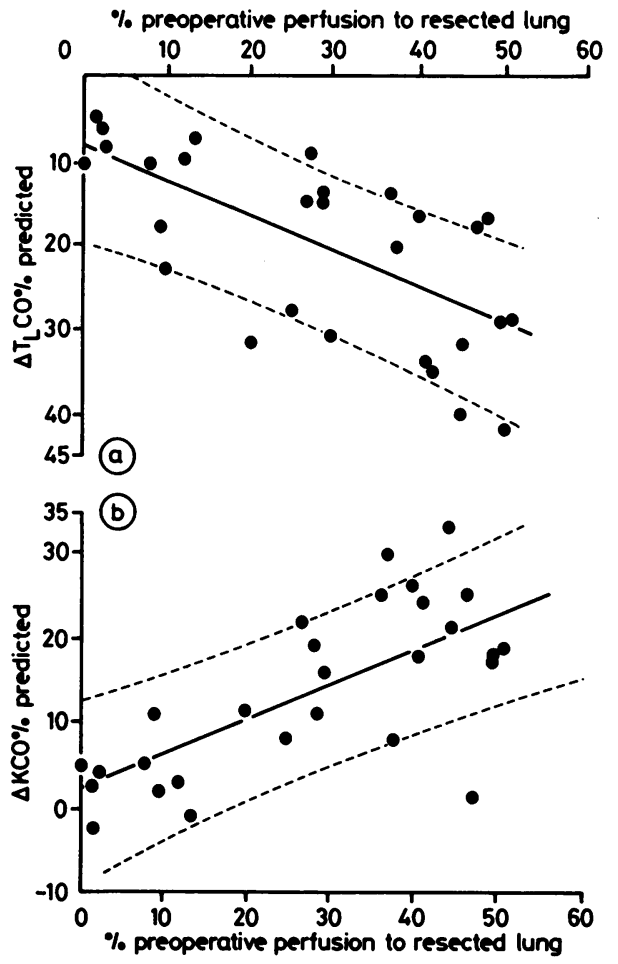

Fig 2 (a) Relationship between observed changes in carbon monoxide transfer factor $(T L C O)(y)$ and percentage preoperative perfusion to resected lung $(x)$ in 28 patients $(r=-0.68, y=-0.4 x-8.6)$. The broken lines indicate 95\% confidence limits $(b)$ Relationship between observed changes in transfer coefficient $(\mathrm{KCO})(y)$ and percentage preoperative perfusion to resected lung $(x)$ in 28 patients, $(r=0.71, y=0.41 x+2 \cdot 1)$. The broken lines indicate $95 \%$ confidence limits.

by means of equation 1 and the perfusion scan data showed good agreement (fig 6).

Table Lung function, exercise performance, and changes after pneumonectomy

\begin{tabular}{|c|c|c|c|c|c|c|c|}
\hline & $\begin{array}{l}F E V_{1} \\
\text { (\% predicted) }\end{array}$ & $\begin{array}{l}V C \\
(\% \text { predicted })\end{array}$ & $\begin{array}{l}V_{A} \\
(\% \text { predicted } \\
T L C)\end{array}$ & $\begin{array}{l}\text { TLCo } \\
\text { (\% predicted) }\end{array}$ & $\begin{array}{l}\text { Kco } \\
\text { (\% predicted) }\end{array}$ & $\begin{array}{l}\dot{V}_{E \max } \\
\left(1 \min ^{-1}\right. \\
B T P S)\end{array}$ & $\begin{array}{l}\dot{V} O_{2} \max \\
\left(1 \min ^{-1}\right. \\
S T P D)\end{array}$ \\
\hline No of patients & 28 & 28 & 28 & 28 & 28 & 14 & 14 \\
\hline $\begin{array}{l}\text { Before operation } \\
\text { Mean } \\
\text { SD } \\
\text { Range }\end{array}$ & $\begin{array}{l}74 \cdot 9 \\
(18 \cdot 6) \\
(35-112)\end{array}$ & $\begin{array}{l}82 \cdot 1 \\
(17 \cdot 6) \\
(45-111)\end{array}$ & $\begin{array}{l}77 \cdot 2 \\
(14 \cdot 5) \\
(43-97)\end{array}$ & $\begin{array}{l}77 \cdot 8 \\
(21 \cdot 2) \\
(36-106)\end{array}$ & $\begin{array}{l}97 \cdot 7 \\
(20 \cdot 5) \\
(39-139)\end{array}$ & $\begin{array}{l}47.9 \\
(16 \cdot 1) \\
(32-85)\end{array}$ & $\begin{array}{l}1 \cdot 4 \\
(0 \cdot 38) \\
(0 \cdot 7-2 \cdot 1)\end{array}$ \\
\hline $\begin{array}{c}\text { Change } \\
\text { Mean } \\
\text { SD } \\
\text { Range }\end{array}$ & $\begin{array}{l}-22 \\
(15 \cdot 5) \\
(+10 \text { to }-56)\end{array}$ & $\begin{array}{l}-28 \cdot 7 \\
(15 \cdot 2) \\
(-5 \text { to }-56)\end{array}$ & $\begin{array}{l}-26 \cdot 7 \\
(13 \cdot 5) \\
(0 \text { to }-48)\end{array}$ & $\begin{array}{l}-20 \cdot 2 \\
(10 \cdot 8) \\
(-5 \text { to }-42)\end{array}$ & $\begin{array}{l}+13 \cdot 6 \\
(9 \cdot 8) \\
(-1 \text { to }+33)\end{array}$ & $\begin{array}{l}-13.6 \\
(9.2) \\
(-1.7 \text { to } \\
-30)\end{array}$ & $\begin{array}{l}-0.324 \\
(0.154) \\
(-0.066 \text { to } \\
-0.626)\end{array}$ \\
\hline
\end{tabular}

VC-vital capacity; VA-effective alveolar volume; TLC-total lung capacity; TLco-carbon monoxide transfer factor;

$\mathrm{Kco}-$ transfer coefficient; $\mathrm{V} E \max -$ maximum ventilation; $\hat{V}_{2} \max -$ maximum oxygen uptake. 

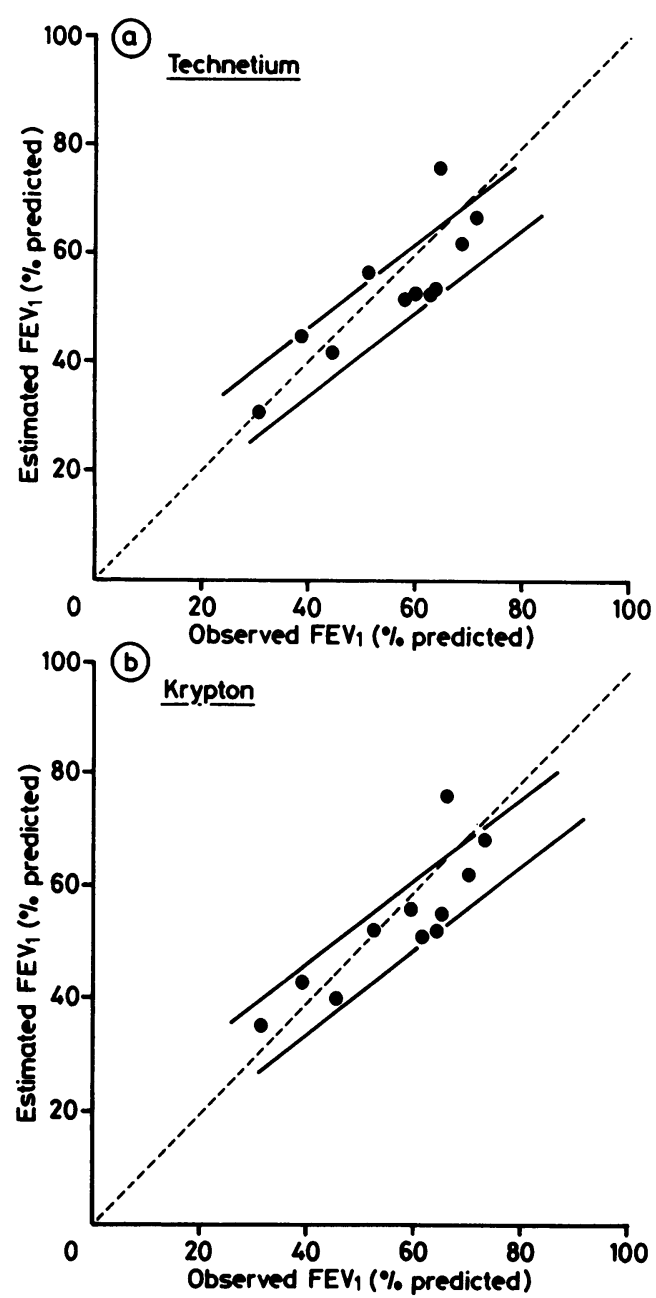

Fig 3 (a) Relationship between estimated (y) and observed $(x)$ values of $F E V_{1}$ expressed as percentage predicted after pneumonectomy in 11 patients from technetium- $99 \mathrm{~m}$ perfusion scans. The broken line represents identity and the solid line the limits within which $95 \%$ of the values of $y$ lie, given $y=x \times$ constant. (b) Relationship between estimated $(y)$ and observed $(x)$ values of $F E V_{1}$ expressed as percentage predicted after pneumonectomy in 11 patients on the basis of krypton-88m ventilation scans. The broken line represents identity and the solid lines the limits within which $95 \%$ of the values of $y$ lie, given $y=x \times$ constant.

\section{Discussion}

Surgery remains the treatment of choice in technically resectable non-small cell bronchial carcinoma. Most patients, however, have some degree of diffuse airways obstruction because the major aetiological

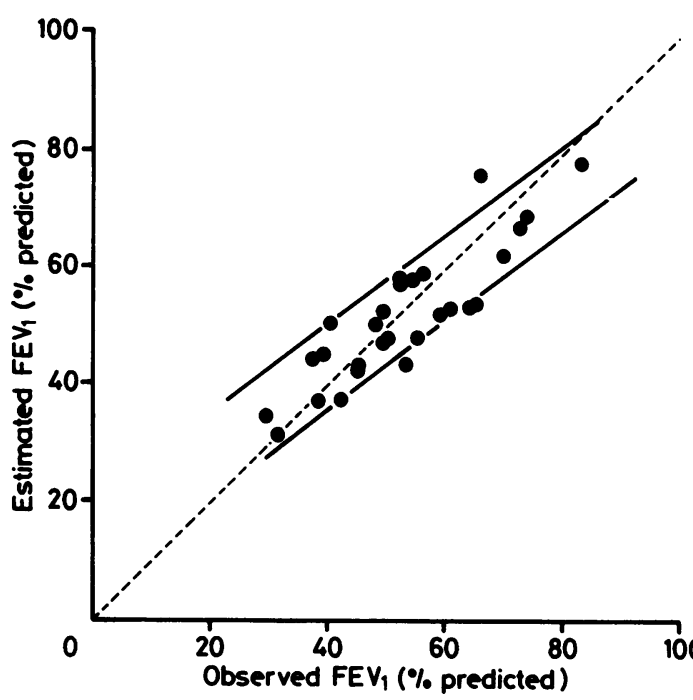

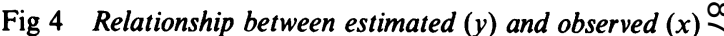
values of $F E V_{1}$ expressed as percentage predicted after pneumonectomy in 28 patients on the basis of technetium$99 \mathrm{~m}$ scans. The broken line represents identity and the solid lines the limits within which $95 \%$ of the values of $y$ lie, given $y=x \times$ constant.

agent, smoking, is common to the two conditions. Accurate estimation of postoperative respiratory function is therefore desirable in many patients to avoid denying potentially curative treatment on the one hand and to avoid severe postoperative disability on the other. Of the various techniques for estimation $x$ of the functional outcome of pneumonectomy for bronchial carcinoma, the perfusion scan is most commonly used, having the advantages of simplicity, widespread availability, and avoidance of discomfort

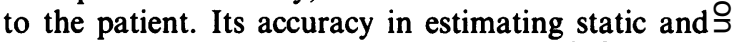
dynamic lung volumes is well established. ${ }^{6-9}$

COMPARISON OF VENTILATION AND PERFUSION SCANS

Use of a perfusion rather than a ventilation scan to estimate postoperative ventilatory measurements may ${ }^{\omega}$ at first sight seem illogical, but when perfusion scans using ${ }^{99 \mathrm{~m}} \mathrm{Tc}$ were compared with ventilation scans ${ }^{\circ}$ using ${ }^{133} \mathrm{Xe}$ the former were found to be more accurate. ${ }^{9}$ Ventilation and perfusion scans are usually ${ }^{-}$ closely matched in patients with bronchial car- $\frac{0}{0}$ cinoma, ${ }^{22}$ but an advantage of perfusion scans over $\overrightarrow{\mathbb{D}}$ xenon ventilation scans is the ease with which both $\frac{}{8}$ anteroposterior and posteroanterior views can be $\varrho$ obtained, and an average value for the contributions? of right and left lungs to overall function may lead to greater accuracy. Standard ventilation scans witho 

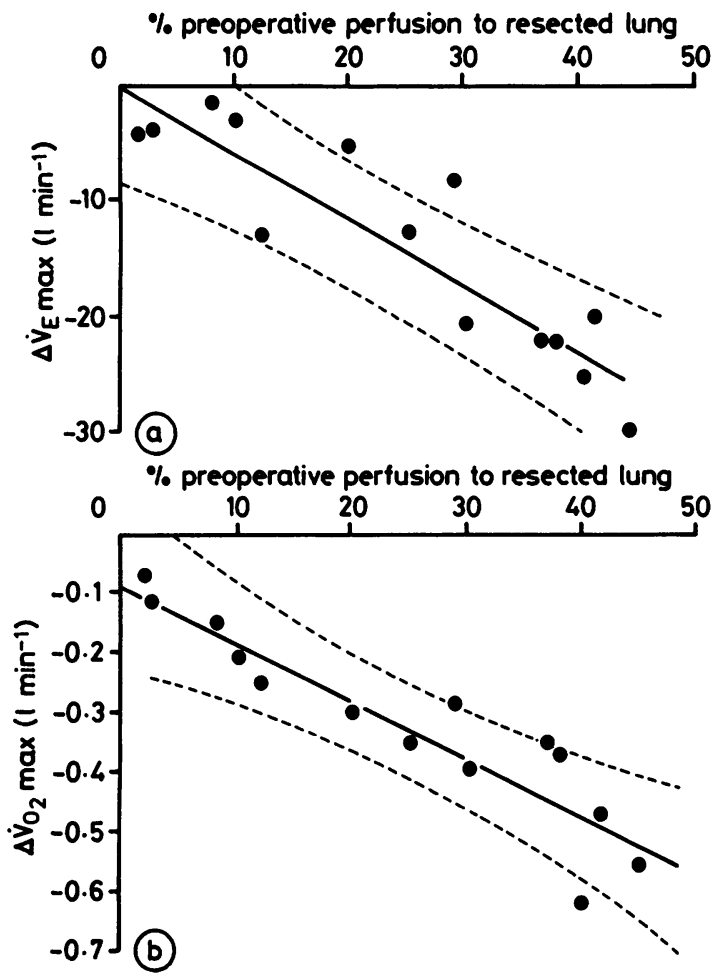

Fig 5 (a) Relationship between observed changes in maximum ventilation ( $\dot{\mathrm{E}} \max (y))$ and percentage preoperative perfusion to resected lung $(x)$ in 14 patients $(r=-0.89, y=-0.56 x-0.03)$. The broken lines indicate 95\% confidence limits. (b) Relationship between observed changes in $\dot{V}_{\mathrm{O}_{2}} \max (y)$ and percentage preoperative perfusion to resected lung $(x)$ in 14 patients $(r=-0.90$, $y=-9.7 x-0.09)$. The broken lines indicate $95 \%$ confidence limits.

xenon usually allow only a single view, but with krypton multiple views are easily obtainable. We have confirmed the suggestion of Lipscomb and Pride ${ }^{11}$ that krypton ventilation scans should give an accurate estimate of postoperative ventilatory function. In the 11 patients studied here, however, the accuracy was no greater than that of ${ }^{99 \mathrm{~m}} \mathrm{Tc}$ perfusion scans, and the more widespread availability of the latter isotope weighs heavily in its favour.

In the comparison of estimated and measured postoperative functional values previous authors ${ }^{6-9} 23$ have generally quoted only the correlation coefficient, which in this context is inadequate ${ }^{18}$ as it fails to give an estimate of the accuracy of the predicted value. In the present series of 28 patients we have plotted $95 \%$ confidence limits and confirmed that the method is sufficiently accurate to be of clinical value.
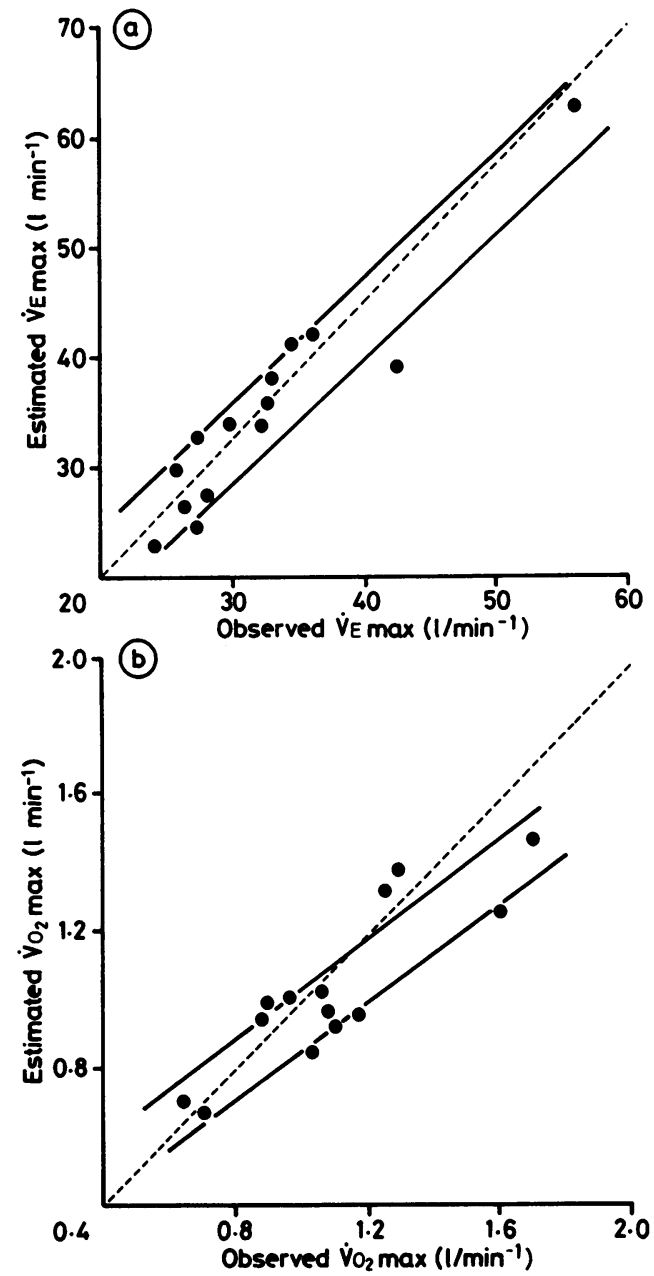

Fig 6 (a) Relationship between estimated (y) and observed (x) values of $\dot{V} E$ max after pneumonectomy in 14 patients on the basis of technetium- $99 \mathrm{~m}$ perfusion scans. The broken line represents identity and the solid lines the limits within which $95 \%$ of the values of $y$ lie, given $y=x \times$ constant. (b) Relationships between estimated $(y)$ and observed $(x)$ values of $\dot{V O}_{2}$ max after pneumonectomy in 14 patients on the basis of technetium- $99 \mathrm{~m}$ perfusion scans. The broken line represents identity and the solid lines the limits within which $95 \%$ of the values of $y$ lie, given $y=x \times$ constant.

\section{CHANGES IN TRANSFER FACTOR AND TRANSFER} COEFFICIENT

We have found significant linear relationships between the postoperative changes in TLCO and KCO and the function of the resected lung as assessed by perfusion scanning. The relationships are, however, more complex than those for ventilatory 
measurements. Although alveolar volume falls approximately in parallel with other lung volumes, the mean change in $\mathrm{KCO}$ is a rise, presumably because of an increase in the capillary blood volume of the remaining lung relative to its gas volume. To take the extreme case, if there is no preoperative blood flow to the lung to be resected clearly there can be no increase in flow to the healthy lung after operation, whereas in a patient with equal blood flow to the two lungs before operation there is potential for an increase of $100 \%$ in blood flow to the healthy lung after pneumonectomy. Unless preoperative perfusion is zero, total transfer factor therefore would be expected to fall after pneumonectomy relatively less than static lung volumes. Although some workers ${ }^{6}$ have attempted to estimate postoperative TLCO using equation 1 , accurate prediction based on this relationship would not be expected and the values calculated would be likely to be less than those observed postoperatively, except in patients with unilaterally absent flow. After operation TLCo and Kco may, however, be estimated by using the empirical relationships established in the present study:

$$
\begin{aligned}
& \text { change in TLCO }(\% \text { predicted })=-0.4 x-8.6 \\
& \text { increase in KCO }(\% \text { predicted })=0.41 x+2.1
\end{aligned}
$$

(where $x$ is percentage perfusion of the lung to be resected).

\section{PREDICTION OF POSTOPERATIVE EXERCISE PER FORMANCE}

Our results showed that the preoperative perfusion scan is a good guide to the change in postoperative exercise tolerance (fig 5), as there were clear relationships between the radionuclide scan assessment of unilateral function and the postoperative falls in both VEmax and $\dot{V}_{2}$ max in a symptom limited progressive exercise test. Moreover, use of equation 1 for estimating postoperative $\dot{\mathrm{V}} \mathrm{Emax}$ and $\mathrm{V}_{2}$ max gave values whose accuracy was comparable with those of the better established spirometric estimates (fig 6). All patients both before and after operation stopped exercise because of shortness of breath, but we did not make a formal assessment of dyspnoea on exercise; possibly the preoperative sensation rather than indices of performance is the major determinant of postoperative symptoms.

In conclusion, we have shown that perfusion scans may be useful to estimate not only postoperative spirometric performance, but also maximum ventilation and oxygen uptake on exercise. Changes in TLCO and KCO are more complex but they also are related to the preoperative distribution of perfusion. Although an estimate of the likely postoperative TLCO and Kco may not have much clinical relevance, it could be of use in the investigation of breathlessness after surgery. If, for example, postoperative mea- $\vec{F}$ surements fell below the range of values expected, $\stackrel{\oplus}{\rightarrow}$ mechanisms other than simple loss of functioning lung (for example, the development of pulmonary $\frac{\bar{\sigma}}{\bar{\omega}}$ hypertension) would merit consideration.

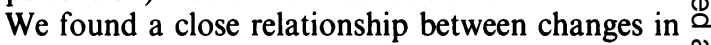
$\mathrm{FEV}_{1}$ and in exercise performance, suggesting that $\stackrel{0}{\circ}$ simple spirometric tests with a perfusion scan should $\vec{\circ}$ suffice in the functional assessment of patients who may need to undergo pneumonectomy. The larger the $\vec{\rho}$ perfusion defect of a lung affected by bronchial carcinoma, the less likely is the tumour to be technically $x$ resectable $^{22}$ but, paradoxically, the smaller is the functional deficit after operation if successful + resection can be performed.

We thank Adrian Kendrick and Yvonne Ferguson for $\stackrel{\circ}{工}$ technical assistance; Sue Murray for typing the $\vec{D}$ manuscript; and $\mathrm{Mr} \mathrm{G} \mathrm{N}$ Morritt, $\mathrm{Mr} \mathrm{C} \mathrm{J}$ Hilton, Mr A H Brown, and the late Mr W C Barnsley for permission to study patients under their care. $P$ A $\mathrm{C}_{\infty}^{\infty}$ was a research fellow funded by the research. committee of Newcastle Health Authority.

\section{References}

1 Neuhaus H. Cherniack NS. A bronchospirometric method estimating the effect of pneumonectomy on the $\overrightarrow{\bar{O}}$ maximum breathing capacity. $J$ Thorac Cardiovasc 3 Surg 1978;55:144-8.

2 Snider GL. Shaw AR. A critical evaluation of bronchospirometric measurement in predicting loss of ventilatory function due to thoracic surgery. $J$ Lab Clin Med $\vec{\partial}$ 1964;64:321-4.

3 Laros CD, Swierenga J. Temporary unilateral pulmonary artery occlusion in the preoperative $\frac{\sigma}{3}$ evaluation of patients with bronchial carcinoma. Med Thorac 1967;24:269-73.

4 Bergan F. A simple method of determination of the relative function of the right and left lung. Acta Chir 음 Scand 1960;253(suppl):58-63.

5 Kristersson S, Lindell SE, Svanberg L. Prediction of pul-은 monary function loss due to pneumonectomy using xenon radiospirometry. Chest 1972;62:694-8.

6 Olsen GN, Block AJ, Tobias JA. Prediction of post- $N$ pneumonectomy pulmonary function using quanti- 요 tative macroaggregate lung scanning. Chest 1974;66: $\omega$ 13-6.

7 Boysen PG, Block AJ, Olsen GN, et al. Prospectivee evaluation for pneumonectomy using the $99 \mathrm{~m}$ technetium quantitative perfusion lung scan. Chest $\stackrel{\oplus}{?}$ 1977;72:422-5.

8 Ali MK, Mountain CF, Ewer MS, Johnston D, Haynie TP. Predicting loss of pulmonary function after pul- $\overrightarrow{\mathbb{D}}$ monary resection for bronchogenic carcinoma. Chest $\frac{}{\mathbb{D}}$ 1980;77:337-42.

9 Wernly JA, De Meester TR, Kirchner PT, Myerowitzo PD, Oxford DE, Golomb HM. Clinical value of quantitative ventilation perfusion lung scans in the surgicalo 
management of bronchogenic carcinoma. Chest $1980 ; 80 ; 535-47$.

10 Fazio F, Jones T. Assessment of regional ventilation by continuous inhalation of radioactive krypton. $\mathrm{Br} \mathrm{Med}$ $J$ 1975;iii:673-6.

11 Lipscomb DJ, Pride NB. Ventilation and perfusion scans in the preoperative assessment of bronchial carcinoma. Thorax 1977;32:720-5.

12 Kanarek DJ, Weigel LB, Blum JE, Kazemi H. Prediction of postoperative exercise tolerance and ventilation capacity by preoperative testing. Am Rev Respir Dis 1980;121:154.

13 Ogilvie CM, Forster RE, Blakemore WS, Morton JW. A standardized breath holding technique for the clinical measurement of the diffusing capacity of the lung for carbon monoxide. J Clin Invest 1957;36:1-17.

14 McGrath MW, Thomson ML. The effect of age, body size and lung volume change on the alveolar-capillary permeability and diffusing capacity in man. $J$ Physiol 1959;146:572-82.

15 Goldman HI, Becklake MR. Respiratory function tests. Normal values at median altitudes and the prediction of normal results Am Rev Tuberc 1959;79:457-67.

16 Kory RC, Callahan R, Boren HG, Syner JC. The Veterans Administration-Army Cooperative Study of pul- monary function. I. Clinical spirometry in normal men. Am J Med 1961;30:243-58.

17 Berglund E, Birath G, Bjure J, et al. Spirometric studies in normal subjects. I. Forced spirograms in subjects between 7 and 70 years of age. Acta Med Scand 1963;173: 185-92.

18 Cotes JE. Lung function: assessment and application in medicine. 3rd ed. Oxford: Blackwell Scientific Publications, 1975

19 Bradley J, Bye C, Hayden SP, Hughes DTD. Normal values of transfer factor and transfer coefficient in healthy males and females. Respiration 1979;38:221-6.

20 Gorlin R, Knowles JH, Storey CF. Effects of thoracotomy on pulmonary function. $J$ Thorac Surg 1957;34:242-9.

21 Altman DG, Bland JM. Measurement in Medicine; the analysis of method comparison studies. The Statistician 1983;32:307-17.

22 Ellis DA, Hawkins T, Gibson GJ, Nariman S. The place of lung scanning in the assessment of resectability of bronchial carcinoma. Thorax 1983;38:261-6.

23 Williams AJ, Cayton RM, Harding LK, et al. Quantitative lung scintigrams and lung function in the selection of patients for pneumonectomy. Br J Dis Chest 1984;78:105-12. 